\title{
Association of STAT6 and ADAM33 single nucleotide polymorphisms with asthma bronchiale and IgE level and its possible epigenetic background
}

\author{
Marek Godava ${ }^{a}$, Frantisek Koprivab , Jana Bohmovaa, Radek Vodickaa , Ladislav Dusekc, Michaela Cvanovac, Jan Muzikc, \\ Marie Markova ${ }^{a}$, Eva Schneiderova ${ }^{a}$, Radek Vrtel ${ }^{a}$
}

Background. ADAM 33 and STAT6 belong to the candidate genes that have been commonly associated with asthma, bronchial hyperresponsiveness or IgE levels. Our objective was to assess the association of 11 SNPs of the ADAM33 and 6 of the STAT6 and their haplotypes with IgE levels and asthma. We also evaluated the possible role of parental origin of haplotypes on IgE levels.

Methods. We enrolled 109 children with asthma and 45 healthy controls. Genotyping was performed by TaqMan probes and confirmed by sequencing. Haplotype construction was based on the knowledge of parental genotypes and also inferred by using the EM algorithm and Bayes' theorem.

Results. None of the SNPs were associated with elevated lgE level or asthma. We found that the most frequent STAT6 haplotype ATTCAA (built from rs324012, rs324011, rs841718, rs3024974, rs3024974, rs4559 SNPs, respectively) was associated with elevated total lgE levels $(P=0.01)$ and this haplotype was predominantly transmitted paternally $(P<0.001)$. We compared our results with those of studies performed on German and Australian Caucasian populations and found that rs324011, rs3024974 and rs4559 SNPs in STAT6 should have a major effect on IgE levels. Therefore, we suggest the TCA haplotype alone (built from rs324011, rs3024974 and rs4559 SNPs, respectively) in STAT6 is associated with total IgE elevation.

Conclusions. The influence of paternal origin of the STAT6 haplotype on IgE levels is surprising but the exact role of possible paternal imprinting in STAT6 regulation should be investigated and confirmed in future studies.

Key words: ADAM33, STAT6, IgE levels, asthma, SNP, parental haplotypes

Received: July 1, 2011; Accepted with revision: January 10, 2010; Available online: January 30, 2012 http://dx.doi.org/10.5507/bp.2012.009

\author{
${ }^{a}$ Department of Medical Genetics and Fetal Medicine, University Hospital Olomouc and Faculty of Medicine and Dentistry, Palacky University \\ Olomouc, Czech Republic \\ ${ }^{b}$ Department of Paediatrics, University Hospital Olomouc and Faculty of Medicine and Dentistry, Palacky University Olomouc \\ 'Institute of Biostatistics and Analyses, Masaryk University Brno \\ Corresponding author: Marek Godava, e-mail: GodavaM@seznam.cz
}

\section{INTRODUCTION}

Asthma is defined as a chronic inflammatory airway disease with recurrent bronchoconstriction caused by stimuli that would otherwise not cause airway narrowing in most individuals. Asthma is a syndrome characterized by airway obstruction that varies both spontaneously and as a result of therapy. The main pathogenic mechanism of bronchial asthma is a special form of chronic inflammation, with many types of cells, in particular eosinophils, and inflammatory mediators influencing the bronchial mucosa. Airway hyperresponsiveness (AHR) is known to be a major risk factor for the development of asthma and to be a surrogate of asthma severity with respect to symptomatic disease. AHR is also reported to be a marker for the subsequent development of asthma in patients with allergic rhinitis. AHR can be defined as an increased sensitivity of the airways to inhaled histamine or methacholine or to exposure to physical stimuli, such as exercise. AHR may represent more than a single entity. It may reflect a common physiological pathway of several mechanisms leading to a lowered threshold of airway narrowing to bronchoconstrictor stimuli. AHR reflects, and is likely partially caused by, airway inflammation. Measurement of bronchial hyper-reactivity provides quantitative insights into variable airflow obstruction.

Asthma has an important genetic component and complex interactions between environment and multiple genes of small to modest effect give rise to the final disease phenotype. In the last decade, several candidate genes responsible for asthma development have been identified. Van Eerdewegh et al. ${ }^{1}$ identified a locus on the short arm of chromosome 20 which was linked to asthma and bronchial hyperresponsiveness. $A D A M 33$, a disintegrin and metalloproteinase 33 , maps to this region (precisely at 20p13), contains 22 exones (Fig. 1) and was significantly associated with asthma. ADAM33 belongs to a subgroup of metalloproteinases. These enzymes are involved in cell fusion, proteolysis, cell adhesion and cell signalling and shedding cell-surface cytokines, growth factors and receptors that are linked with inflammation and cell death events. ADAM33 is expressed by lung fibroblasts and bron- 


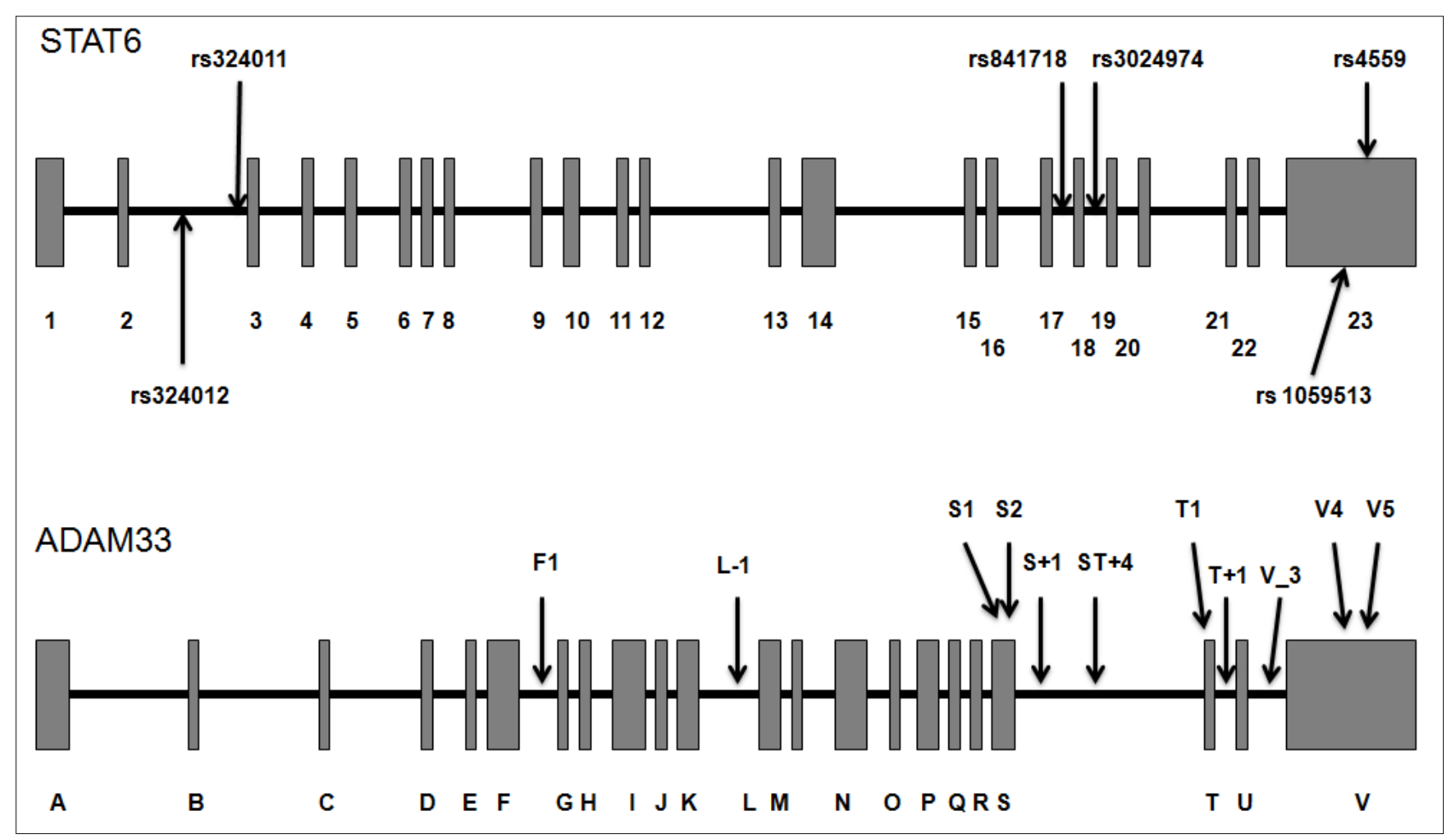

Fig. 1. Structure of the STAT6 and ADAM33. Upper part shows structure of the STAT6, lower part shows ADAM33 structure there are exons and SNPs investigated in our study.

chial smooth-muscle cells ${ }^{1}$ and according to the site specific expression, $A D A M 33$ is suggested to be responsible for hypertrophy of airway smooth muscles, subsequently leading to bronchial hyperresponsiveness and activation of the $\mathrm{Th}_{2}$-mediated allergic reaction. The role of ADAM33 in inducing myogenesis is supported by structural similarity with ADAM12 (ref. $^{3}$ ). The secreted form of $A D A M 12$ (ADAM12-S) was shown to provoke myogenesis in smooth muscle of airways ${ }^{4}$. Many of the $A D A M 33$ polymorphisms (SNPs) were studied and several of them were associated with asthma in some studies ${ }^{1,2}$ but not in others ${ }^{3,4}$. Each of the SNPs probably contributes with their own small effect to overall asthma manifestation and so haplotype association studies are more promising. Eederwegh et al. found 8 haplotypes (made of V4, V1, V-1, T1 and S1 SNPs) that were significantly overtransmitted to affected offspring at $P<0.005$ level $^{1}$. Howard et al. evaluated association of $A D A M 33$ SNPs with asthma in different populations and found that no single haplotype accounted for asthma susceptibility risk across all of the studied groups. However, some of the haplotypes showed significant difference within studied populations. The GGCGTCCG haplotype in the Dutch population, GGAGTCCC haplotype in the US white (Caucasian) population and GCAATCAG in the US African American population were more common in the patients compared with those in the control group ${ }^{2}$. An association study of three SNPs performed on the Chinese Han population didn't find any significant association between the SNPs or haplotypes in $A D A M 33$ with adult asthma ${ }^{5}$. In contrast, $\mathrm{H} 1, \mathrm{H} 3, \mathrm{H} 5$ and $\mathrm{H} 8$ haplotypes (made of $\mathrm{F}+1, \mathrm{~T}+1, \mathrm{~T} 2, \mathrm{~T} 1, \mathrm{~V} 4$, and Q-1 SNPs) were strongly associated with child asthma in the Han Chinese population in northern China ${ }^{6}$. The AGCCT, GGCCT, AGACT, GCAGT, GGACT, ACCCC and AGACC haplotypes (made of F+1, S2, ST4, ST5 and V4 SNPs) were positively associated with asthma in the Indian adult population ${ }^{7}$. Many studies have shown linkage of the chromosomal locus 12q13-24 to asthma or associated phenotypes, such as elevated $\operatorname{IgE}$ level ${ }^{8-10}$. A signal transducer and activator of transcription 6 (STAT6), as one of the asthma candidate genes, was found in this region and some of the association studies focused on the STAT6 SNPs have shown their linkage to IgE levels ${ }^{11,12}$. Human STAT6 is located on 12q13.3-14.1 and contains 23 exons $^{13}$ (Fig. 1). The STAT6 plays a crucial role in allergic response mediated by IL-4 and IL-13, because of its association with both IL-4 and IL-13 receptors ${ }^{14}$. First contact with an allergen leads to stimulation of specific $\mathrm{Th}_{2}$ lymphocyte clones, they produce several cytokines such as IL-4, which stimulate B lymphocytes to produce IgE. IL-4 signals through two receptors - major IL-4 receptor (type I receptor) and type II receptor (also transmits IL-13 signal) (ref. ${ }^{15}$ ). IL-4 binds to the IL-4R $\alpha$ chain which is common for both of the receptors ${ }^{16}$. Next, this complex binds to the $\gamma \mathrm{c}$ chain and creates a complete, active receptor ${ }^{17}$. However, IL-4 receptor is unable to transmit a signal by itself, so JAK kinases are required. JAK1 and 3 associate with the IL-4R $\alpha$ and $\gamma \mathrm{c}$ receptor subunit, respectively ${ }^{18,19}$. Binding of IL-4 to its receptor leads to phosphorylation and transphosphorylation of the associated JAK kinases, which in turn lead to phosphorylation of three Tyr residues Y575, Y603, and Y631 in IL-4R $\alpha$ chain $^{20,21}$. These phosphotyrosines provide docking sites for STAT6 monomers, which in turn become phosphory- 


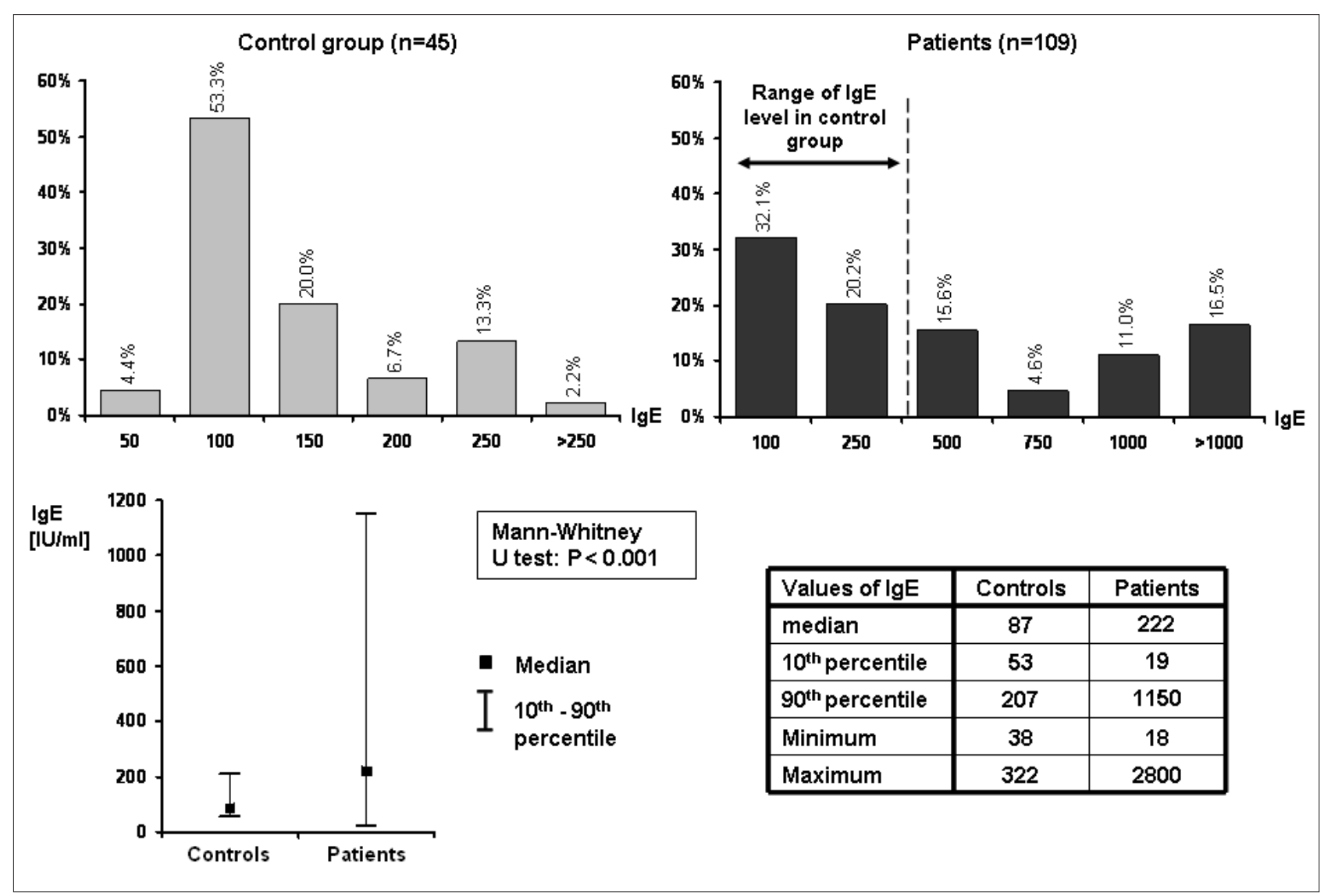

Fig. 2. Total IgE levels in patient and control group.

Upper part: distribution of IgE levels. Lower part: box plot and summary statistics.

* Statistically significant difference between the groups (t-test on logarithmically transformed data)

lated by the associated JAK kinases. Activated STAT6 monomers are able to form dimers and are transported to the nucleus, where they bind to highly conserved DNA motifs - TTC C/A NN G/T GAA and C/T TTC NNN (N) GAA G/A (ref. ${ }^{22}$ ) - found in promoters of IL-4 and IL-13 inducible genes. This leads to Ig class switching and activation of genes responsible for $\operatorname{IgE}$ production. IgE production actually requires 2 signals. The first is the above described IL-4 or IL-13 mediated signaling, which promotes switch recombination by activating the $\mathrm{C} \varepsilon$ gene. The second is direct interaction of CD40 surface antigen on B cell with its ligand (CD40L) located on activated $T$ cells. The latter signal leads to deletional switch recombination $^{23-25}$. The IL-4 driven IgE synthesis is upregulated by IL-6, but IL- 6 alone in combination with IL-4 alone are not sufficient to induce IgE production ${ }^{26}$. Alternatively, IgE production could be regulated via IL-4 signaling in cooperation with CD58 of B cells with its ligand CD2. The CD58 driven IgE production is CD40 and IL-6 independent ${ }^{27}$. Interaction between cell surface molecules is also an important costimulatory signal for IgE synthesis. The costimulatory signal provided by ligation of CD21, CD54 and CD58 on the B cell with their ligands up-regulates IgE production ${ }^{27-30}$. CD23 is another molecule regulated by factors increasing or decreasing $\mathrm{IgE}$ production. CD23 interacts with CD21 on B cells and antibodies to CD23 cause inhibition of IL-4 dependent IgE produc- tion. Therefore the CD23/CD21 pair has been suggested to preferentially drive IgE production ${ }^{31}$. Another potent costimulant of $\operatorname{IgE}$ synthesis is CD86 of tonsilar B cells. CD86 is a ligand for CD28 expressed on T cells. CD86, together with IL-4 or IL-13, favors CD23-CD21 pairing and provides a selective and potent costimulus for the increase in IgE synthesis ${ }^{32}$. Contribution of STAT6 SNPs to the risk of asthma or IgE level has been studied in several populations. The C2892T (rs324011) polymorphism in the second intron of STAT6 has been repeatedly associated with elevated $\mathrm{IgE}$ in the German population ${ }^{11}$. The T12888C (rs 1059513) and A4671G (rs4559) have also showed a significant link with elevated IgE level in the German population ${ }^{11,12}$. Nagarkatti et al. ${ }^{33}$ identified and associated the CA repeating polymorphism ( $\mathrm{R} 1$ locus) in the promoter region of STAT6 with atopic asthma in the Indian population. This relationship between SNP and $\operatorname{IgE}$ has not been observed in the German population ${ }^{11}$. As discussed for ADAM33, the effect of the STAT6 SNPs should cumulate in their haplotypes. In the southwestern German population, the main haplotype GCTCAA (made from rs2598483, rs3001428, rs324011, rs3024974, rs 1059513, rs4559 SNPs) was seen to significantly increase IgE level, GCCTAG haplotype was a significant risk for the development of specific sensitisation and haplotype ACCCAG was associated with an increased risk of asthma ${ }^{21}$. However, a combined German - Swedish 
study assessing the effect of 13 SNPs in STAT6 on asthma development or elevated IgE level didn't find any association of STAT6 haplotypes with asthma or IgE level ${ }^{11}$. The $17 \_15$ and 16_15 haplotypes of CA repeat polymorphisms in $\mathrm{R} 1$ and $\mathrm{R} 3$ regions (respectively) of the STAT6 promotor were found to be positively associated with asthma in the Indian population ${ }^{33}$. Another study conducted on the German population found haplotype CGTGTT to be associated with elevated $\operatorname{IgE}\left(\right.$ ref. ${ }^{12}$ ).

Environmental influences and epigenetic mechanisms could pose important modifying factors shaping the phenotype at a clinical level. Risk of asthma development has been associated with antenatal and childhood exposure to tobacco smoke $\mathrm{k}^{34,35}$ mainly in individually predisposed persons such as carriers of the Arg16 allele in the $\beta 2$-adrenergic receptor gene ${ }^{36}$. Intake of folic acid in supplement form was associated with increased risk of asthma in childhood (at 3.5 years) and with persistent asthma $^{37}$. Conversely, maternal exposures to an environment rich in microbial compound may pose a protective effect $^{38}$. Methylation and histone acetylation belong to the important epigenetic mechanisms of gene expression. Increase in histone acyltransferase with decrease in histone deacetylase was observed in asthma ${ }^{39}$. Furthermore, inhibition of methyltransferase increased expression of STAT6 mRNA and protein rather than variants in exon $1\left(\right.$ ref. $\left.^{40}\right)$.

The aim of this study was to find out whether STAT6 and $A D A M 33$ SNPs are associated with total IgE levels in our population. We performed genotyping of some previously reported polymorphisms in these genes and examined possible association of these polymorphisms and haplotypes with asthma or atopy in families with children who have asthma. In addition, we also evaluated the possible role of parental origin of haplotypes on total IgE levels.

Table 1. Frequencies of $A D A M 33$ SNPs. The first nucleotide in each SNP represents the major allele, thus homozygote 1 is homozygote for the major allele.

Patients (n=109)

\begin{tabular}{|c|c|c|c|c|c|c|c|c|c|c|c|}
\hline SNP/ Genotypes & 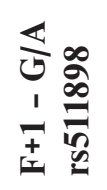 & 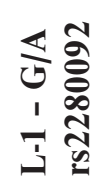 & 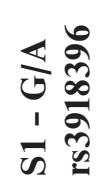 & 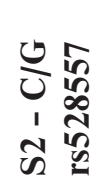 & 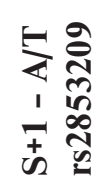 & 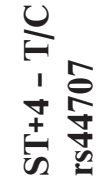 & 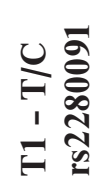 & 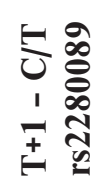 & 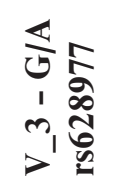 & 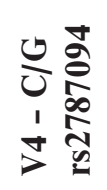 & 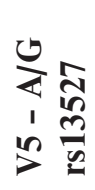 \\
\hline Homozygote 1 & 0.29 & 0.63 & 0.86 & 0.45 & 0.37 & 0.39 & 0.61 & 0.62 & 0.73 & 0.60 & 0.87 \\
\hline Heterozygote & 0.53 & 0.34 & 0.14 & 0.42 & 0.45 & 0.47 & 0.35 & 0.36 & 0.25 & 0.38 & 0.12 \\
\hline Homozygote 2 & 0.17 & 0.03 & 0.00 & 0.13 & 0.18 & 0.15 & 0.05 & 0.03 & 0.03 & 0.03 & 0.01 \\
\hline Alleles & $\mathbf{G}-\mathbf{A}$ & $\mathbf{G}-\mathbf{A}$ & $\mathbf{G}-\mathbf{A}$ & $\mathbf{C}-\mathbf{G}$ & $\mathbf{A}-\mathbf{T}$ & $\mathbf{T}-\mathbf{C}$ & $\mathbf{T}-\mathbf{C}$ & $\mathbf{C}-\mathbf{T}$ & $\mathbf{G}-\mathbf{A}$ & $\mathbf{C}-\mathbf{G}$ & $A-G$ \\
\hline Major allele & 0.56 & 0.80 & 0.93 & 0.66 & 0.59 & 0.62 & 0.78 & 0.79 & 0.85 & 0.78 & 0.93 \\
\hline Minor allele & 0.44 & 0.20 & 0.07 & 0.34 & 0.41 & 0.38 & 0.22 & 0.21 & 0.15 & 0.22 & 0.07 \\
\hline
\end{tabular}

Control group $(n=45)$

\begin{tabular}{|c|c|c|c|c|c|c|c|c|c|c|c|}
\hline SNP/ Genotypes & 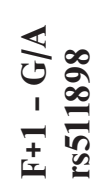 & 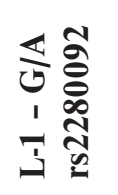 & 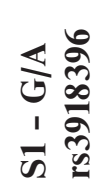 & 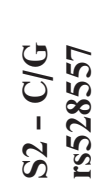 & 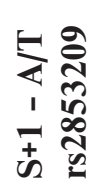 & 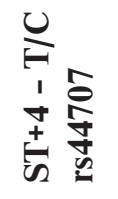 & 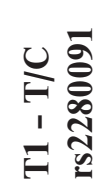 & 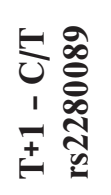 & 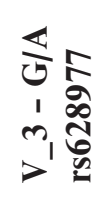 & 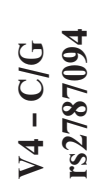 & 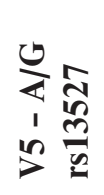 \\
\hline Homozygote 1 & 0.33 & 0.69 & 0.80 & 0.47 & 0.31 & 0.42 & 0.69 & 0.60 & 0.76 & 0.60 & 0.91 \\
\hline Heterozygote & 0.49 & 0.27 & 0.18 & 0.40 & 0.49 & 0.42 & 0.27 & 0.36 & 0.20 & 0.38 & 0.09 \\
\hline Homozygote 2 & 0.18 & 0.04 & 0.02 & 0.13 & 0.20 & 0.16 & 0.04 & 0.04 & 0.04 & 0.02 & 0.00 \\
\hline Alleles & $\mathbf{G}-\mathbf{A}$ & $\mathbf{G}-\mathbf{A}$ & $\mathbf{G}-\mathbf{A}$ & $\mathbf{C}-\mathbf{G}$ & $A-T$ & $\mathbf{T}-\mathbf{C}$ & $\mathbf{T}-\mathbf{C}$ & $\mathrm{C}-\mathrm{T}$ & $\mathbf{G}-\mathbf{A}$ & $C-G$ & A - G \\
\hline Major allele & 0.58 & 0.82 & 0.89 & 0.67 & 0.56 & 0.63 & 0.82 & 0.78 & 0.86 & 0.79 & 0.96 \\
\hline Minor allele & 0.42 & 0.18 & 0.11 & 0.33 & 0.44 & 0.37 & 0.18 & 0.22 & 0.14 & 0.21 & 0.04 \\
\hline
\end{tabular}




\section{MATERIALS AND METHODS}

\section{Subjects}

Our study was performed on a population of 109 children with bronchial asthma and their relatives (parents and sibs), overall 375 persons in 108 families, and 45 controls from the general population. The study was approved by the Palacky University Hospital Ethics Committee. The parents of all children, who participated in this study, gave their signed informed consent. The diagnosis of persistent mild atopic bronchial asthma (a positive skin prick test) was established, using the GINA 2002 guidelines, in 109 children ( 76 boys and 35 girls) aged $0.4-20$ years (median 11 years), referred to the Department of Allergology of the Department of Paediatrics in 2003-2005. In all patients, atopic status was evaluated by skin prick test- ing using common allergen extracts (grass and tree pollen, house dust mite, moulds, cat/dog extracts). IgE level was determined in both the patient and control group with a highly significant difference between the groups $(P<0.01$, Fig. 2).

\section{Genotyping and haplotyping}

DNA samples were isolated from peripheral blood by standard salting out method. Genotypes in patients and their relatives and controls were identified by using allele discrimination/SNP's real time PCR. The probes for discrimination/SNP's real time PCR were obtained from the Applied Biosystem database of TaqMan SNP genotyping assays or designed by the manufacturer according to our specifications. The PCR reaction was carried out in overall volume of $10 \mu \mathrm{l}$ with these components: $6.28 \mu \mathrm{l}$

Table 2. Frequencies of STAT6 SNPs. The first nucleotide in each SNP represents the major allele, thus homozygote 1 is homozygote for the major allele.

Patients (n=109)

\begin{tabular}{|c|c|c|c|c|c|c|}
\hline SNP/ Genotypes & 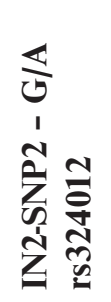 & 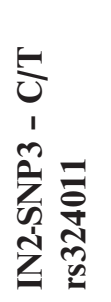 & 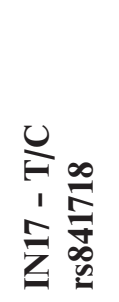 & 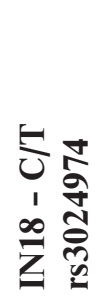 & 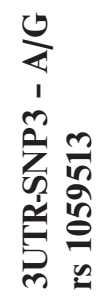 & 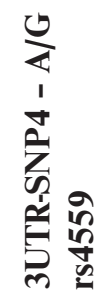 \\
\hline Homozygote 1 & 0.28 & 0.37 & 0.30 & 0.81 & 0.88 & 0.34 \\
\hline Heterozygote & 0.48 & 0.42 & 0.53 & 0.18 & 0.11 & 0.54 \\
\hline Homozygote 2 & 0.25 & 0.21 & 0.17 & 0.01 & 0.01 & 0.12 \\
\hline Alleles & $\mathbf{G}-\mathbf{A}$ & $\mathbf{C}-\mathrm{T}$ & $\mathbf{T}-\mathbf{C}$ & $C-T$ & $A-G$ & $A-G$ \\
\hline Major allele & 0.51 & 0.58 & 0.57 & 0.90 & 0.94 & 0.61 \\
\hline Minor allele & 0.49 & 0.42 & 0.43 & 0.10 & 0.06 & 0.39 \\
\hline
\end{tabular}

Control group $(n=45)$

\begin{tabular}{|c|c|c|c|c|c|c|}
\hline SNP/ Genotypes & 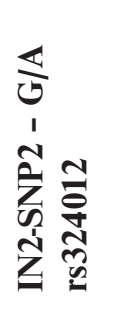 & 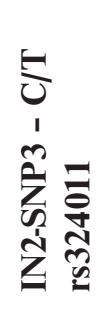 & 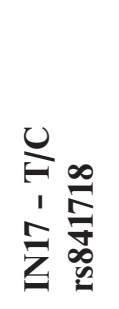 & 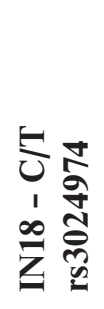 & 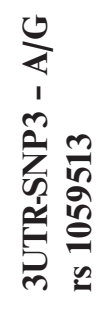 & 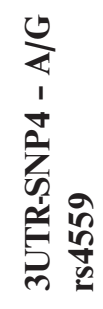 \\
\hline Homozygote 1 & 0.31 & 0.31 & 0.42 & 0.89 & 0.89 & 0.44 \\
\hline Heterozygote & 0.53 & 0.56 & 0.47 & 0.11 & 0.11 & 0.51 \\
\hline Homozygote 2 & 0.16 & 0.13 & 0.11 & 0.00 & 0.00 & 0.04 \\
\hline Alleles & $\mathbf{G}-\mathbf{A}$ & $C-T$ & $\mathbf{T}-\mathbf{C}$ & $C-T$ & $A-G$ & $\mathbf{A}-\mathbf{G}$ \\
\hline Major allele & 0.58 & 0.59 & 0.66 & 0.94 & 0.94 & 0.70 \\
\hline Minor allele & 0.42 & 0.41 & 0.34 & 0.06 & 0.06 & 0.30 \\
\hline
\end{tabular}


Table 3. Frequency of $A D A M 33$ and STAT6 haplotypes in individuals with determined haplotypes.

\begin{tabular}{|c|c|c|c|c|c|}
\hline & Haplotype & Code & $\begin{array}{c}\text { Patients } \\
\text { [\%] }\end{array}$ & $\begin{array}{c}\text { Controls } \\
{[\%]}\end{array}$ & p-value \\
\hline & 11112111111 & a1 & 27.1 & 30.0 & 0.792 \\
\hline$A D A M 33$ & 11111211111 & a2 & 22.9 & 25.0 & 0.783 \\
\hline $\mathrm{n}=\mathbf{1 4 0}$ haplotypes in patients & 22121122111 & a3 & 16.4 & 10.0 & 0.742 \\
\hline \multirow[t]{2}{*}{$\mathrm{n}=20$ haplotypes in controls } & 11111211121 & & 8.6 & 15.0 & 0.405 \\
\hline & 21111211111 & & 6.4 & 10.0 & 0.630 \\
\hline \multirow{4}{*}{$\begin{array}{l}\text { STAT6 } \\
\mathrm{n}=168 \text { haplotypes in patients } \\
\mathrm{n}=22 \text { haplotypes in controls }\end{array}$} & 221111 & s1 & 39.9 & 50.0 & 0.368 \\
\hline & 112112 & s2 & 27.4 & 9.1 & 0.071 \\
\hline & 111111 & s3 & 11.9 & 4.5 & 0.477 \\
\hline & 212212 & & 4.8 & 0.0 & 0.600 \\
\hline
\end{tabular}

$$
\begin{array}{ll:ll}
\hline \text { ADAM33 } & \text { STAT6 } \\
\hline 1-G & 2-A & 1-G & 2-A \\
1-G & 2-A & 1-C & 2-T \\
1-G & 2-A & 1-T & 2-C \\
1-C & 2-G & 1-C & 2-T \\
1-A & 2-T & 1-A & 2-G \\
1-T & 2-C & 1-A & 2-G \\
1-T & 2-C & - & \\
1-C & 2-T & & \\
1-G & 2-A & & \\
1-C & 2-G & & \\
1-A & 2-G & &
\end{array}
$$

\begin{tabular}{|c|c|c|c|c|c|c|}
\hline & At least one $s 1$ & $\begin{array}{l}\text { Level of IgE } \\
\text { [IU/ml] }\end{array}$ & $\begin{array}{c}\text { Paternal } \\
\text { s1 }\end{array}$ & $\begin{array}{l}\text { Level of IgE } \\
\text { [IU/ml] }\end{array}$ & $\begin{array}{c}\text { Maternal } \\
\text { s1 }\end{array}$ & $\begin{array}{l}\text { Level of IgE } \\
\text { [IU/ml] }\end{array}$ \\
\hline & Yes $(59.5 \%)$ & $612(19 ; 2450)$ & Yes $(40.5 \%)$ & $814(39 ; 2590)$ & Yes $(39.3 \%)$ & $642(19 ; 2590)$ \\
\hline \multirow[t]{3}{*}{ All $(\mathrm{N}=84)$} & No $(40.5 \%)$ & $309(18 ; 1220)$ & No $(59.5 \%)$ & $269(18 ; 1150)$ & No $(60.7 \%)$ & $390(18 ; 1220)$ \\
\hline & $P$-value & 0.014 & P-value & $<0.001$ & $P$-value & 0.218 \\
\hline & Yes $(54.2 \%)$ & $768(54 ; 2800)$ & Yes $(37.5 \%)$ & $923(102 ; 2800)$ & Yes $(33.3 \%)$ & $866(54 ; 2800)$ \\
\hline \multirow[t]{3}{*}{ Female (N=24) } & No $(45.8 \%)$ & $376(18 ; 2060)$ & No $(62.5 \%)$ & $388(18 ; 2060)$ & No $(66.7 \%)$ & $450(18 ; 2060)$ \\
\hline & $P$-value & 0.022 & $P$-value & 0.018 & P-value & 0.106 \\
\hline & Yes $(61.7 \%)$ & $557(19 ; 2450)$ & Yes $(41.7 \%)$ & $774(39 ; 2450)$ & Yes $(41.7 \%)$ & $571(19 ; 2450)$ \\
\hline \multirow[t]{2}{*}{ Male (N=60) } & No $(38.3 \%)$ & $277(34 ; 1150)$ & No $(58.3 \%)$ & $218(18 ; 1150)$ & No $(58.3 \%)$ & $363(19 ; 1220)$ \\
\hline & P-value & 0.191 & P-value & $<0.001$ & $P$-value & 0.759 \\
\hline
\end{tabular}

The table displays only haplotypes with a frequency rate $>4 \%$ (in patients). Legend shows alphanumerical code for haplotype denotation, 1 stands for major allele and 2 stands for minor allele of the studied SNPs. The haplotypes are made from F+1, L_1, S1, S2, S +1, ST +4 , T1, T+1, V_3, V4 and V5 SNPs (respectively) in ADAM33 and IN2-2, IN2-3, IN17, IN18, 3'UTR-3, 3'UTR-4 (respectively) in STAT6. Differences between patients and controls in haplotype frequencies were computed with Fisher's exact test (2 sided).

Table 4. Parental origin of s1 haplotype related to the difference in total IgE levels.

The table shows values of IgE of patients according to parental origin of $\mathrm{s} 1$ haplotype in males and females.

IgE: mean values $\left(5^{\text {th }}-95^{\text {th }}\right.$ percentiles $)$

$P$-value of Mann-Whitney $\mathrm{U}$ test comparing IgE levels in patients with and without haplotype s1 
$\mathrm{H}_{2} \mathrm{O}, 0.02 \mu \mathrm{l}$ reference dye Rox 50X (Finnzymes), $4.0 \mu \mathrm{l}$ DyNamo $^{\text {TM }}$ Probe qPCR Kit F-450S/L (Finnzymes), $0.2 \mu \mathrm{SNP}$ genotyping assay (Applied Biosystem) and $0.5 \mu \mathrm{LNA}(100 \mathrm{ng} / \mu \mathrm{l})$. Allele discrimination PCR was run on Stratagene MxPro3005 thermal cycler under the following conditions: starting denaturation at $95{ }^{\circ} \mathrm{C}$ for $15 \mathrm{~min}$ and then 55 cycles including denaturation at $95^{\circ} \mathrm{C}$ for $15 \mathrm{~s}$ followed by annealing/synthesis step at $60{ }^{\circ} \mathrm{C}$ for $1 \mathrm{~min}$. The $\mathrm{dRn}$ values (baseline subtracted fluorescent reading normalized to the reference dye) were used to determine fluorescence $c_{T}$ values. Difference in $c_{T}$ values and shape of curves from fluorescence readings $(\mathrm{dRn}$ data) were used to determine genotypes.

Observed genotypes were confirmed by direct sequencing of the SNPs of interest in 15 patients and their relatives, overall 50 persons of 15 families. The sequencing reaction was carried out in a volume of $10 \mu \mathrm{l}$ with reagents obtained from Applied Biosystems, reaction mixture contained: $2 \mu \mathrm{l}$ of primer, $2 \mu \mathrm{l}$ of PCR water (Top-Bio), $2 \mu \mathrm{l}$ of purified PCR amplicons and $4 \mu \mathrm{l}$ of ABI PRISM ${ }^{\circledR}$ Big Dye ${ }^{\circledR}$ Terminator v 3.1 (4-times diluted by $5 \mathrm{x}$ sequencing buffer). Sequence reaction ran under the following thermal conditions: denaturation at $94{ }^{\circ} \mathrm{C}$ for $2 \mathrm{~min}$ and 34 cycles of $96^{\circ} \mathrm{C}$ for $10 \mathrm{~s}$, with gradual $1{ }^{\circ} \mathrm{C}$ per $1 \mathrm{~s}$ temperature decreasing to $50{ }^{\circ} \mathrm{C}, 50{ }^{\circ} \mathrm{C}$ for $5 \mathrm{~s}$ and $60{ }^{\circ} \mathrm{C}$ for $4 \mathrm{~min}$. After the sequencing reaction and products purification (ethanol precipitation), capillary electrophoresis was performed on ABI PRISM ${ }^{\mathrm{TM}} 310$ Genetic Analyzer (Applied Biosystems).

Haplotypes and their parental origin were determined according to genotypes of patients' parents. Nonconclusive haplotypes were inferred by using expectation maximization algorithm modified by partition ligation mode ${ }^{41}$ and also using Bayes' theorem ${ }^{42}$.

\section{Statistics}

Hardy - Weinberg equilibrium (HWE) was tested with the $\chi^{2}$-test between patients and controls separately. Standard non-parametric statistics were used to describe primary data, i.e. absolute and relative frequencies, median and $10^{\text {th }}-90^{\text {th }}$ percentile range. ML- $\chi^{2}$ test and Fisher's exact test were applied to compare differences among variants in categorical variables. Content of $\operatorname{IgE}$ as the only quantitative variable in the study revealed asymmetric sample distribution of log-normal type. Therefore, the data were log-transformed, $X_{t r}=\ln (X+1)$ and comparisons of groups (one-way ANOVA, t-test) were performed on the transformed data. The transformation proved effective in normalizing the IgE distribution (Shapiro-Wilk's test). The transformed IgE values revealed homogeneous variance in groups of patients and controls (Levene's test). Final assessment of the relationship between $\mathrm{IgE}$ levels and haplotypes was performed by non-parametric Mann-Whitney test using primary IgE data.
Table 5. Frequencies of the most common haplotypes in our study compared to results from two other studies on Caucasian population.

The haplotypes were constructed from rs324011, rs3024974, rs4559 SNPs (respectively) of STAT6 SNPs. TCA $=\mathrm{s} 1, \mathrm{CCG}=\mathrm{s} 2, \mathrm{CCA}$ $=\mathrm{s} 3$ haplotype.

\begin{tabular}{cccc}
\hline Haplotype & $\begin{array}{c}\text { Our } \\
\text { population }\end{array}$ & Weidinger & Duetsch \\
\hline TCA & 43.68 & 37.51 & 42.82 \\
CCG & 26.84 & 26.00 & 15.87 \\
CCA & 20.52 & 25.04 & 23.30 \\
\hline
\end{tabular}

\section{RESULTS}

Genotypes and allele frequencies of the studied genes ADAM33 and STAT6 SNPs were successfully determined in all studied patients, their relatives (parents and sibs) and in the control group (45 children) as well. All of the studied SNPs were in HWE in both patients and controls $(P>0.05)$. We found some differences in allele frequencies of studied SNPs between patients and control group, but these differences didn't reach a level of statistical significance (Tables 1,2).

According to knowledge of parental genotypes in studied ADAM33 and STAT6 SNPs, we constructed haplotypes in patients. The haplotypes were successfully determined in $64.2 \%(\mathrm{~N}=70)$ for $A D A M 33$ and in $77.1 \%(\mathrm{~N}=84)$ for STAT6 in the patient group and in $22.2 \%(\mathrm{~N}=10)$ for ADAM33 and in $24.4 \%(\mathrm{~N}=11)$ for STAT6 in the control group. For each of the studied genes we found three of the most common haplotypes (with frequency above $10.0 \%$ in patients); they were marked as a1-3 for ADAM33 and s1-3 for STAT6, in descending order according to their frequency rate. The frequency of the most common haplotypes was not significantly different between patients and control group (Table 3 ). We were unable to analyze minor haplotypes, but their mild contribution (together as a group) to final asthma phenotype can't be ruled out.

We tested association of ADAM33 and STAT6 haplotypes with IgE levels. All of the three most common haplotypes (a1-3, s1-3) showed a tendency to be linked to increased IgE levels. Statistical significance was only reached in case of STAT6 haplotypes (Fig. 3). An elevated level of IgE is linked mainly to s 1 haplotype (STAT6) and moreover there were differences in $\mathrm{s} 1$ haplotype distribution according to parental origin. Seventy-three and one-half percent of patients with IgE levels > $200 \mathrm{IU} / \mathrm{ml}$ shared haplotype of paternal origin vs. $57.6 \%$ of patients with maternal origin of $\mathrm{s} 1$ haplotype. This relationship of s1 haplotype to total IgE levels was significant for haplotype of paternal origin $(P<0.01)$ and marginally for haplotype from maternal line, too $(P=0.08)$. 


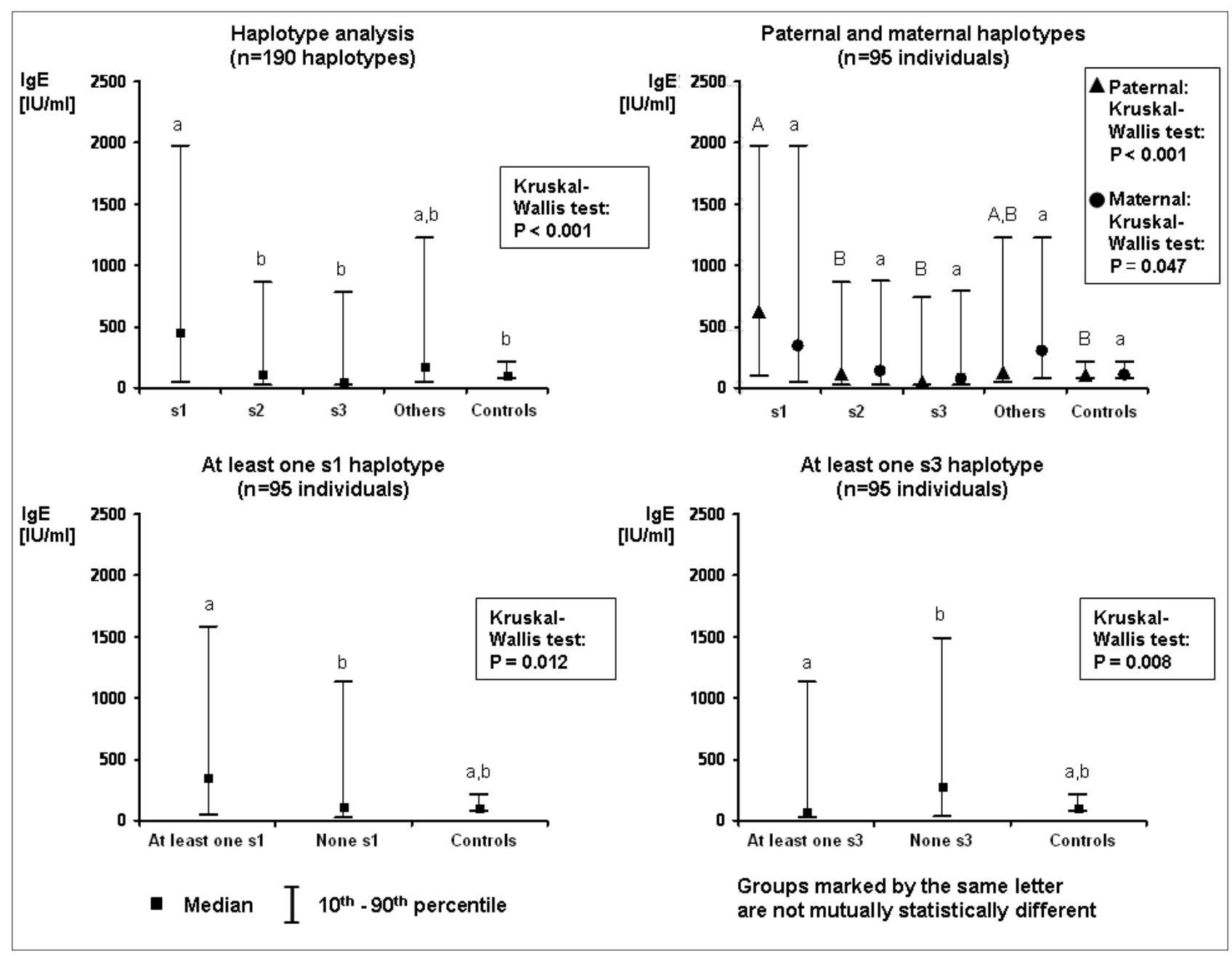

Fig. 3. STAT6 haplotypes in relation to total IgE levels.

Upper part documents the relation of STAT6 haplotypes to IgE levels and influence of maternal and paternal origin of haplotypes to IgE levels. Lower part describes the link of haplotypes to total IgE levels in presence of one certain haplotype (without consideration of its parental origin).

A, B/a, b: marks of homogeneous groups; groups marked by the same letter are not mutually statistically different $(P<0.05$; pairwise multiple comparison with Bonferroni correction)

We performed an analysis of combined paternal and maternal haplotypes in an attempt to assess their contribution to IgE levels (Table 4). Patients with increased IgE levels shared at least one s1 haplotype $(P=0.01)$ and the subgroup of females with at least one s1 haplotype showed differences in $\operatorname{IgE}$ levels $(P=0.02)$. We subsequently analyzed the effect of parental origin of s1 haplotype on total IgE levels. The median value of total IgE was higher in patients with paternally transmitted s1 haplotype $(P<0.01$, $618 \mathrm{IU} / \mathrm{ml}$ in patients with s1 haplotype versus $115 \mathrm{IU} / \mathrm{ml}$ without). The difference in total $\mathrm{IgE}$ distribution related to paternal s1 haplotype was also observed when evaluating males and females separately. Paternal origin of s1 haplotype showed a tendency to elevate IgE levels in males $(P<0.001)$, as well as in females $(P=0.02)$. Differences in $\mathrm{IgE}$ levels were not observed when evaluating transmission of s1 haplotype from maternal line. The other STAT6 haplotypes also correlated with IgE levels, although their linkage is not as significant as for $\mathrm{s} 1$, and so the effects on IgE levels by them can't be distinguished.
ADAM33 haplotypes did not reveal such significant linkage to elevated IgE levels, as was seen in STAT6 haplotypes. There was observed increased IgE variation among patients with particular ADAM33 haplotypes, therefore haplotype effect on IgE levels can't be significantly determined. The a2 haplotype represents the only exception showing slightly elevated IgE levels, but without exact statistical significance $(P=0.26)$. Also analysis of combined ADAM33 haplotypes did not reveal significant relationship with IgE levels.

\section{DISCUSSION}

In this study, we investigated an influence of 6 SNPs of STAT6 on asthma and total IgE levels, all of them in intronic or UTR regions. Hence none of the SNPs reached significant level (Table 2), some of the SNPs (such as In 2 - SNP3) were more often present in patients with asthma or with increased total IgE levels. This result was 
not surprising because some of these SNPs (such as In2SNP3, In 17, In18, 3UTR-SNP4) were associated with elevated total IgE levels, or with decline in lung function $\left(\mathrm{FEV}_{1}\right)$ in some studies ${ }^{11,12,43}$ but not in others ${ }^{12,44}$. This difference could be explained by different patient group size in the studies, however, international studies working with hundreds/thousands of asthma patients of Caucasian origin didn't find statistically significant differences in the distribution of investigated polymorphisms between the group of asthmatics and the control group ${ }^{43,44}$. This fact points to the small contribution of the SNPs to the studied phenotype and possibly to individual differences in SNPs distribution inside the examined populations as well. The group size was relatively small but the number of subjects was sufficient to reach statistical significance, as seen also in similar studies ${ }^{11,45}$. Frequencies of genotyped SNPs were similar to SNP frequencies reported in similar studies (In2-SNP3, In 18 and 3UTR SNP4 polymorphism investigated in this study as well as in German studies), differences in allelic frequencies were up to $5 \%$ (ref. ${ }^{9,45}$ ) and the allelic frequencies were also similar compared to the population of asthmatics in a study of 1500 subjects by Schedel et al. ${ }^{12}$.

Haplotype analysis revealed that the most common STAT6 haplotype - s1 haplotype (ATTCAA) - is significantly associated with the elevation of total IgE levels. To compare our results with published data, we focused on SNPs common to our and other (German) studies (In2SNP3, In 18 and 3UTR SNP4). We used these three SNPs to determine haplotypes - the frequencies of the most frequent haplotypes were almost the same as the frequencies

Table 6. Frequencies of the most frequent $A D A M 33$ haplotypes in patient groups from our and German ${ }^{59}$ studies. The haplotypes are built from SNPs common for the studies: F+1, S1, S2, ST+4, T1 and V4.

\begin{tabular}{ccc}
\hline Haplotype & $\begin{array}{c}\text { German } \\
\text { Caucasian }\end{array}$ & $\begin{array}{c}\text { Czech } \\
\text { Caucasian }\end{array}$ \\
\hline GGCTTC & 31.59 & 23.16 \\
GGCCTC & 16.63 & 20.00 \\
AGGTCC & 14.00 & 14.74 \\
GGCCTG & 11.22 & 7.89 \\
\hline
\end{tabular}

Table 7. Frequencies of the most frequent $A D A M 33$ haplotypes in patient groups from our and Australian ${ }^{58}$ studies. The haplotypes are built from SNPs common for the studies: F+1, S1, ST+4, V4 and V5.

\begin{tabular}{ccc}
\hline Haplotype & Australian & Czech \\
\hline GGTCA & 34.00 & 27.1 \\
GGCCA & 17.00 & 23.6 \\
AGTCA & 13.00 & 20.0 \\
GGCGA & 10.00 & 8.6 \\
\hline
\end{tabular}

of haplotypes built from all examined SNPs, so we used the same names for these "refined" haplotypes (s1, s2 and s3). The same procedure was applied in published data. Although our population is different from the German one, we found that both SNPs frequencies and haplotype frequencies in our population were also similar to published German populations. Our s1 and s2 haplotypes had similar frequencies as the haplotypes no. 1 and 5 respectively published by Weidinger et al. ${ }^{45}$ and haplotypes no. 1 and 3 published by Duetsch et al. ${ }^{11}$ (Table 5). One small exception was s 3 haplotype with greater difference in frequency in our and German studies.

In light of these findings, we suggest that the following SNPs have the greatest effect on IgE levels: rs324011, rs3024974, rs4559, respectively. Haplotype TCA built up from these SNPs is associated with IgE levels. Of these three SNPs, the first one is probably the most "potent" one, since Schedel et al. in 2004 (ref. ${ }^{12}$ ) proved its influence on elevated total IgE levels. They revealed two putative transcription factor binding (TFB) sites - nuclear factor $\kappa \mathrm{B}(\mathrm{NF}-\kappa \mathrm{B})$ by computer analysis of the STAT6 second intron sequence. Both the STAT6 and the NF$\mathrm{\kappa B}$ binding to target sequence is required to induce $\operatorname{IgE}$ production. The two TFB sites in the second intron are very close to each other and the $\mathrm{T}$ allele of rs324011 gives rise to the distal one. Sequence at the site of this SNP is strongly conserved among primates ${ }^{12}$. In a functional study, Schedel et al. ${ }^{46}$ confirmed that the T allele of rs324011 increases STAT6 promoter activity by creating a new site for NF- $\kappa \mathrm{B}$ specific binding. In expression analysis, they discovered two new STAT6 isoforms - STAT6d and STAT6e. Patients with asthma bearing the TT genotype in rs324011 had a mild, but not significant, increase of the known STAT6 form and significantly increased level of STAT6d and STAT6e mRNA. However, the role of the two isoforms on IgE production is still unclear. According to their results, they predicted physical interaction of intron 2 with the promoter region and subsequent change of the STAT6 3D structure or its epigenetic signature caused by NF- $\kappa \mathrm{B}$ binding ${ }^{46}$.

In the last years, researchers pointed out that environmental and epigenetic factors have an important impact on the final atopy or asthma phenotype ${ }^{47}$. The main epigenetic mechanisms are histone acetylation and DNA methylation ${ }^{47,48}$. For example, the DNA methylation has been implicated in Th2 cell differentiation. Hence the third CpG residue in rad50 hypersensitive site 7 (RHS7) of the Th2 LCR (locus control region) in naive T cells were almost fully methylated ( $96 \%)$, the Th2 cells showed complete demethylation in the RHS7 and this occurred in a STAT6-dependent manner ${ }^{49}$.

The parental origin of atopy or asthma has been discussed for a long time. Reduced risk of asthma and AHR in children has been associated with Val105 polymorphism of GSTP1 (glutathione S-transferase) in the mother ${ }^{50}$. Transmission of atopy from maternal line was observed for locus 11q13 (ref. ${ }^{51}$ ). Infants with elevated cord blood IgE had a higher risk of developing asthma and elevated IgE in cord blood was associated with mater- 
nal atopy ( ref. $^{52}$ ). At the present time the maternal influence is believed to have the greatest influence on atopy or asthma development. In our study, we also attempted to examine the role of parental origin of STAT6 haplotypes on total IgE levels in the patients. Surprisingly, we observed that s1 haplotype (associated with elevation of total IgE levels) was significantly more often transmitted from the paternal line. The mean IgE value in asthma patients was slightly higher in females. The paternally transmitted s1 haplotype showed a higher tendency to increase the total IgE level than maternally inherited haplotype and this effect was stronger in males (Table 4). This different quantity of haplotype effect according to parental origin may be due to a distinct imprinting pattern of the alleles. Some genes are able to fully or partially escape epigenetic reprogramming during prenatal development ${ }^{47,53}$ and so they can preserve their special DNA methylation pattern. Moreover, the specific epigenetic pattern can be transmitted to the descendant, in other words the epigenetic changes may be transmitted transgenerationally ${ }^{53,54}$. These processes could at least partially explain the difference in total IgE levels. We hypothesize that paternally inherited s1 haplotype by itself confers greater risk to the elevation of total IgE. This effect is modulated in utero by the mother, as e.g. maternal behaviour and diet could influence epigenetic programming of the fetus ${ }^{53}$. The gender related difference in distribution of total $\operatorname{IgE}$ levels would probably be attributed to other loci than STAT6 as suggested by some reports ${ }^{50,55-57}$. Although the observed s 1 parental origin related to the difference in total IgE levels according to gender is interesting, the size of subgroups (patients were subsequently divided according to their gender) is relatively small and the observed results must be evaluated to rule out an influence of small numbers.

We attempted to assess the possibility of association of 11 SNPs in $A D A M 33$ with atopy or asthma in our population. We observed differences in SNP distribution between asthmatics and control group, but they were not significant. We compared allele frequencies and frequencies of the most frequent haplotypes (constructed from SNP common for evaluated studies) from our study with published data from Caucasian populations ${ }^{58,59}$ and we found that the frequencies of SNPs were similar (data not shown). As seen for STAT6 haplotypes, some of the $A D A M 33$ haplotypes had a greater frequency difference in our and the two studies (Tables 6,7) $\left(\right.$ ref. $\left.^{58,59}\right)$. The haplotype analysis didn't find any association with asthma. Three major haplotypes (named a1-3) showed a relation to elevated total IgE levels, but without statistical significance. The evidence may reflect the role of $A D A M 33$ in intercellular adhesion because its disintegrin domain supports $\alpha 9 \beta 1$ - integrin dependent leukocyte adhesion ${ }^{60}$ and expression of integrin in mesenchymal cells (such as fibroblasts and smooth muscle cells) (ref. $\left.{ }^{61}\right)$. The combinations of SNP genotypes in haplotypes could influence disintegrin domain function in intercellular adhesion and therefore possibly partially influence the quantity of leukocytes (and thus the inflammation reaction itself) in airways. This observation points to the fact that ADAM33 has an important role in the development of non-atopic asthma.
However, studies with a large size of investigated subjects (at least thousands) and meta-analysis are required to confirm the exact role of $A D A M 33 \mathrm{SNP}$ and haplotype role in disease development.

The investigated genes are part of a signalling pathway or are connected onto greater pathways in which they are complexly interacting together. Undermaa et al. ${ }^{62}$ investigated the reproducibility of the 23 most promising asthma and asthma-related candidate genes in the Japanese population. They found that interactions between IL4RA and $\mathrm{C} 3$, and TBXA2R and ADAM33 were suggested to increase the risk for childhood and all asthma (childhood and adult asthma together). In the middle Chinese population, significant gene-gene interaction was detected between IL-4 -C33T, IL-13 R130Q, IL-4Ralpha I75V, IL4Ralpha Q576R, STAT6 C2892T, and CD14 -C159T in the risk of pediatric asthma ${ }^{63}$. Therefore assessing genegene interaction or interaction of SNPs in genes implicated in asthma or IgE level is a very important task for further investigation.

\section{CONCLUSIONS}

Results of our study, as well as results of similar studies on persons of Caucasian origin, indicate that polymorphisms rs324011, rs3024974 and rs4559 in STAT6 have a major influence on total IgE level. Haplotype analysis revealed that the TCA haplotype alone (constructed from those polymorphisms) in STAT6 is associated with total IgE elevation. Moreover, the haplotype predominantly originated from the fathers of investigated patients. The influence of paternal origin of the STAT6 haplotype on $\mathrm{IgE}$ levels is therefore surprising but the exact role of possible paternal imprinting in STAT6 regulation should be investigated and confirmed in future studies.

\section{CONFLICT OF INTEREST STATEMENT}

Author's conflict of interest disclosure: The authors stated that there are no conflicts of interest regarding the publication of this article.

\section{REFERENCES}

1. Van Eerdewegh P, Little RD, Dupuis J, Del Mastro RG, Falls K, Simon J, Torrey D, Pandit S, McKenny J, Braunschweiger K, Walsh A, Liu Z, Hayward B, Folz C, Manning SP, Bawa A, Saracino L, Thackston M, Benchekroun Y, Capparell N, Wang M, Adair R, Feng Y, Dubois J, FitzGerald MG, Huang H, Gibson R, Allen KM, Pedan A, Danzig MR, Umland SP, Egan RW, Cuss FM, Rorke S, Clough JB, Holloway JW, Holgate ST, Keith TP. Association of the ADAM33 gene with asthma and bronchial hyperresponsiveness. Nature 2002;418:426-30.

2. Howard TD, Postma DS, Jongepier H, Moore WC, Koppelman GH, Zheng SL, Xu J, Bleecker ER, Meyers DA. Association of a disintegrin and metalloprotease 33 (ADAM33) gene with asthma in ethnically diverse populations. J Allergy Clin Immunol 2003;112:717-22.

3. Lind DL, Choudhry S, Ung N, Ziv E, Avila PC, Salari K, Ha C, Lovins EG, Coyle NE, Nazario S, Casal J, Torres A, Rodriguez-Santana JR, Matallana H, Lilly CM, Salas J, Selman M, Boushey HA, Weiss ST, Chapela R, Ford JG, Rodriguez-Cintron W, Silverman EK, Sheppard 
D, Kwok PY, González Burchard E. ADAM33 is not associated with asthma in Puerto Rican or Mexican populations. Am J Respir Crit Care Med 2003;168:1312-6.

4. Zhang $X$, Su D, Zhang $X$, Sui H, Jin L, Lü F, Zhang J. Association of ADAM33 gene polymorphisms with adult concomitant allergic rhinitis and asthma in Chinese Han population. Mol Biol Rep 2008;36:1505-9.

5. Wang P, Liu QJ, Li JS, Li HC, Wei CH, Guo CH, Gong YQ. Lack of association between ADAM33 gene and asthma in a Chinese population. Int J Immunogenet 2006;33:303-6.

6. Qu S, Sun D, Wang Y, Zhang C, Lv Y, Yao L. Association of ADAM33 polymorphisms with childhood asthma in a northern Chinese population. Exp Mol Pathol Published online first: 9 September 2011. doi:10.1016/j.yexmp.2011.09.001

7. Tripathi P, Awasthi S, Prasad R, Husain N, Ganesh S. Association of ADAM33 gene polymorphisms with adult-onset asthma and its severity in an Indian adult population. J Genet 2011;90:265-73.

8. Wilkinson J, Grimley S, Collins A, Thomas NS, Holgate ST, Morton $\mathrm{N}$. Linkage of asthma to markers on chromosome 12 in a sample of 240 families using quantitative phenotype scores. Genomics 1998:53:251-9.

9. Immervoll T, Loesgen S, Dütsch G, Gohlke H, Herbon N, Klugbauer S, Dempfle A, Bickeböller H, Becker-Follmann J, Rüschendorf F, Saar K, Reis A, Wichmann HE, Wjst M. Fine mapping and single nucleotide polymorphism association results of candidate genes for asthma and related phenotypes. Hum Mutat 2001;18:327-36.

10. Barnes KC, Freidhoff LR, Nickel R, Chiu YF, Juo SH, Hizawa N, Naidu RP, Ehrlich E, Duffy DL, Schou C, Levett PN, Marsh DG, Beaty TH. Densemapping of chromosome 12q13.12-q23.3 and linkage to asthma and atopy. J Allergy Clin Immunol 1999;104:485-91.

11. Duetsch G, Illig T, Loesgen S, Rohde K, Klopp N, Herbon N, Gohlke H, Altmueller J, Wjst M. STAT6 as an asthma candidate gene: polymorphism screening, association and haplotype analysis in a Caucasian sib-pair study. Hum Mol Gen 2002;11:613-21.

12. Schedel M, Carr D, Klopp N, Woitsch B, Illig T, Stachel D, Schmid I, Fritzsch C, Weiland SK, von Mutius E, Kabesch M. A signal transducer and activator of transcription 6 haplotype influences the regulation of serum IgE levels. J Allergy Clin Immunol 2004;114:1100-5.

13. Patel BK, Keck CL, O'Leary RS, Popescu NC, LaRochelle WJ. Localization of the human stat6 gene to chromosome 12q13.3q14.1, a region implicated in multiple solid tumors. Genomics 1998;52:192-200

14. Shirakawa I, Deichmann KA, Izuhara I, Mao I, Adra CN, Hopkin JM. Atopy and asthma: genetic variants of II-4 and II-13 signaling Immunol Today 2000;21:60-4.

15. Hebenstreit D, Wirnsberger G, Horejs-Hoeck J, Duschl A. Signaling mechanisms, interaction partners, and target genes of STAT6. Cytokine \& Growth Factor Reviews, 2006;17:173-88.

16. Chatila TA. Interleukin-4 receptor signaling pathways in asthma pathogenesis. Trends Mol Med 2004;10(10):493-9.

17. Mueller TD, Zhang JL, Sebald W, Duschl A. Structure, binding, and antagonists in the IL-4/IL-13 receptor system. Biochim Biophys Acta 2002;1592(3):237-50.

18. Yin T, Tsang ML, Yang YC. JAK1 kinase forms complexes with interleukin-4 receptor and $4 \mathrm{PS} /$ insulin receptor substrate-1-like protein and is activated by interleukin-4 and interleukin-9 in T lymphocytes. J Biol Chem 1994;269:26614-17.

19. Miyazaki ., Kawahara A, Fujii H, Nakagawa Y, Minami Y, Lui ZJ, Oishi I, Silvennoinen O, Witthuhn BA, Ihle JN, Taniguchi T. Functional activation of Jak 1 and Jak3 by selective association with IL-2 receptor subunits. Science 1994,66:1045-7.

20. Hou J, Schindler U, Henzel WJ, Ho TC, Brasseur M, McKnight SL. An interleukin-4-induced transcription factor: IL-4 Stat. Science 1994;265:1701-6.

21. Ryan JJ, McReynolds $L J$, Huang $H$, Nelms K, Paul WE. Characterization of a mobile Stat6 activation motif in the human IL-4 receptor. $J$ Immunol 1998;161:1811-21.

22. Kraus J, Borner C, Hollt V. Distinct palindromic extensions of the 5 - TTC...GAA-3' motif allow STAT6 binding in vivo. FASEB J, 2003;17(2):304-6

23. Jabara HH, Fu SM, Geha RS, Vercelli D. CD40 and IgE: synergism between anti-CD40 monoclonal antibody and interleukin 4 in the induction of IgE synthesis by highly purified human B cells. J Exp Med 1990;172(6):1861-4.
24. Bacharier LB, Geha RS. Molecular mechanisms of IgE regulation. J Allergy Clin Immunol 2000;105:S547-58.

25. Zhang K, Clark EA, Saxon A. CD40 stimulation provides an IFNgamma-independent and IL-4-dependent differentiation signal directly to human B cells for IgE production. J Immunol 1991;146(6):1836-42.

26. Vercelli D, Jabara HH, Arai K, Yokota T, Geha RS. Endogenous interleukin 6 plays an obligatory role in interleukin 4-dependent human IgE synthesis. Eur J Immunol 1989;19(8):1419-24.

27. Diaz-Sanchez D, Chegini S, Zhang K, Saxon A. CD58 (LFA-3) stimulation provides a signal for human isotype switching and IgE production distinct from CD40. J Immunol1994;153(1):10-20.

28. Aubry JP, Pochon S, Graber P, Jansen KU, Bonnefoy JY. CD21 is a ligand for CD23 and regulates IgE production. Nature 1992;358(6386):5057.

29. Pochon S, Graber P, Yeager M, Jansen K, Bernard AR, Aubry JP, Bonnefoy JY. Demonstration of a second ligand for the low affinity receptor for immunoglobulin $\mathrm{E}(\mathrm{CD} 23)$ using recombinant $\mathrm{CD} 23$ reconstituted into fluorescent liposomes. J Exp Med 1992;176(2):38997.

30. Katada Y, Tanaka T, Ochi H, Aitani M, Yokota A, Kikutani H, Suemura $M$, Kishimoto T. B cell-B cell interaction through intercellular adhesion molecule-1 and lymphocyte functional antigen-1 regulates immunoglobulin $E$ synthesis by $B$ cells stimulated with interleukin-4 and anti-CD40 antibody. Eur J Immunol 1996;26(1):192-200.

31. Bonnefoy JY, Gauchat JF, Life P, Graber P, Aubry JP, Lecoanet-Henchoz S. Regulation of IgE synthesis by CD23/CD21 interaction. Int Arch Allergy Immunol 1995;107(1-3):40-2.

32. Jeannin P, Delneste $Y$, Lecoanet-Henchoz $S$, Gauchat JF, Ellis J, Bonnefoy JY. CD86 (B7-2) on human B cells. A functional role in proliferation and selective differentiation into lgE- and lgG4-producing cells. J Biol Chem 1997;272(25):15613-9.

33. Nagarkatti R, B-Rao Ch, Vijayan V, K. Sharma SK, Ghosh B. Signal Transducer and Activator of Transcription 6 Haplotypes and Asthma in the Indian Population. American journal of respiratory cell and molecular biology 2004;31:317-21.

34. Magnusson L, Olesen A, Wennborg H, Olsen J. Wheezing, asthma, hayfever, and atopic eczema in childhood following exposure to tobacco smoke in fetal life. Clin Exp Allergy 2005;35:1550-6.

35. Alati R, Al Mamun A, O'Callaghan M, Najman JM, Williams GM. In utero and postnatal maternal smoking and asthma in adolescence. Epidemiology 2006;17:138-44.

36. Wang C, Salam MT, Islam T, Wenten M, Gauderman WJ, Gilliland FD. Effects of In Utero and Childhood Tobacco Smoke Exposure and beta2-Adrenergic Receptor Genotype on Childhood Asthma and Wheezing. Pediatrics 2008;122:e107-14.

37. Whitrow MJ, Moore VM, Rumbold AR, Davies MJ. Effect of Supplemental Folic Acid in Pregnancy on Childhood Asthma: A Prospective Birth Cohort Study. Am J Epidemiol 2009;170:1486-93.

38. Ege MJ, Bieli C, Frei R, van Strien RT, Riedler J, Ublagger E, SchramBijkerk D, Brunekreef B, van Hage M, Scheynius A, Pershagen G, Benz MR, Lauener R, von Mutius E, Braun-Fahrländer C and Parsifal Study team. Prenatal farm exposure is related to the expression of receptors of the innate immunity and to atopic sensitization in school-age children. J Allergy Clin Immunol 2006;117:817-23.

39. Barnes PJ, Adcock IM and Ito K. Histone acetylation and deacetylation: importance in inflammatory lung diseases. Eur Respir J, 2005:25:552-63.

40. Kim EG, Shin HJ, Lee CG, Park HY, Kim YK, Park HW, Cho SH, Min KU, Cho ML, Park SH, Lee CW. DNA methylation and not allelic variation regulates STAT6 expression in human T cells. Clin Exp Med 2010;10(3):143-52. Epub 2009 Dec 1.

41. Qin ZS, Niu T, Liu JS. Partition-Ligation-Expectation-Maximization Algorithm for Haplotype Inference with Single-Nucleotide Polymorphisms. Am J Hum Genet 2002,70:1242-7.

42. Stephens M, Donnelly P. A comparison of Bayesian methods for haplotype reconstruction from population genotype data. Am J Hum Genet 2003;73:1162-9.

43. Daley $D$, Lemire $M$, Akhabir $L$, Chan-Yeung $M$, He JQ, McDonald $T$ Sandford A, Stefanowicz D, Tripp B, Zamar D, Bosse Y, Ferretti V, Montpetit A, Tessier MC, Becker A, Kozyrskyj AL, Beilby J, McCaskie PA, Musk B, Warrington N, James A, Laprise C, Palmer LJ, Paré PD, Hudson TJ. Analyses of associations with asthma in four asthma 
population samples from Canada and Australia. Hum Genet 2009;125:445-59.

44. Pykäläinen $M$, Kinos $R$, Valkonen $S$, Rydman P, Kilpeläinen $M$, Laitinen LA, Karjalainen J, Nieminen M, Hurme M, Kere J, Laitinen T, Lahesmaa R. Association analysis of common variants of STAT6, GATA3, and STAT4 to asthma and high serum IgE phenotypes. J Allergy Clin immun 2005;115:1100-05.

45. Weidinger S, Klopp N, Wagenpfeil S, Rümmler L, Schedel M, Kabesch M, Schäfer T, Darsow U, Jakob T, Behrendt H, Wichmann HE, Ring J, Illig T. Association of a STAT 6 haplotype with elevated serum IgE levels in a population based cohort of white adults. J Med Genet 2004;41:658-63.

46. Schedel M, Frei R, Bieli C, Cameron L, Adamski J, Lauener R, Kabesch M. An IgE-associated polymorphism in STAT6 alters NF-kB binding, STAT6 promoter activity, and mRNA expression. J Allergy Clin Immunol 2009;124:583-9.

47. Martino DJ, Prescott SL. Silent mysteries: epigenetic paradigms could hold the key to conquering the epidemic of allergy and immune disease. Allergy 2010;65:7-15.

48. Biel M, Wascholowski V, Giannis A. Epigenetics - An epicenter of gene regulation: histones and histone-modifying enzymes. Angew Chem Int Ed Engl 2005;44:3186-216.

49. Kim ST, Fields PE, Flavell RA. Demethylation of a specific hypersensitive site in the Th2 locus control region. Proc Natl Acad Sci USA 2007;104:17052-7.

50. Child F, Lenney W, Clayton S, Davies S, Jones PW, Alldersea JE, Strange RC, Fryer AA. The association of maternal but not paternal genetic variation in GSTP1 with asthma phenotypes in children. Respir Med 2003;97:1247-56.

51. Cookson WOCM, Young RP, Sandford AJ, Moffatt MF, Shirakawa T, Sharp PA, Faux JA, Julier C, Le Souef PN, Nakumura Y, Lathrop GM, Hopkin JM. Maternal inheritance of atopic IgE responsiveness on chromosome 11q. Lancet 1992;340:381-4.

52. Magnusson CG. Cord serum IgE in relation to family history and as predictor of atopic disease in early infancy. Allergy 1988;43:241-51.

53. Dolinoy DC, Das R, Weidman JR, Jirtle RL. Metastable epialleles, imprinting, and the fetal origins of adult diseases. Pediatr Res 2007;61:30R-37R.
54. Rakyan VK, Chong S, Champ ME, Cuthbert PC, Morgan HD, Luu KV, Whitelaw E. Transgenerational inheritance of epigenetic states at the murine Axin(Fu) allele occurs after maternal and paternal transmission. Proc Natl Acad Sci USA 2003;100:2538-43.

55. Raby BA, Soto-Quiros ME, Avila L, Lake SL, Murphy A, Liang C, Fournier E, Spesny M, Sylvia JS, Verner A, Hudson TJ, Klanderman BJ, Freimer NB, Silverman EK, Celedón JC. Sex-specific linkage to total serum immunoglobulin $\mathrm{E}$ in families of children with asthma in Costa Rica. Hum Mol Genet, 2007;16:243-53.

56. Hunninghake GM, Lasky-Su J, Soto-Quirós ME, Avila L, Liang C, Lake SL, Hudson TJ, Spesny M, Fournier E, Sylvia JS, Freimer NB, Klanderman BJ, Raby BA, Celedón JC. Sex-stratified Linkage Analysis Identifies a Female-specific Locus for IgE to Cockroach in Costa Ricans. Am J Resp Crit Care Med 2008;177:830-6.

57. Rigoli L, Salpietro DC, Lavalle R, Cafiero G, Zuccarello D, Barberi I. Allelic association of gene markers on chromosome 1 lq in Italian families with atopy. Acta Paediatr 2000;89:1056-61.

58. Kedda MA, Duffy DL, Bradley B, O'Hehir RE, Thompson PJ. ADAM33 haplotypes are associated with asthma in a large Australian population. Eur J Hum Genet 2006;14:1027-36.

59. Schedel M, Depner M, Schoen C, Weiland SK, Vogelberg C, Niggemann B, Lau S, Illig T, Klopp N, Wahn U, von Mutius E, Nickel $\mathrm{R}$, Kabesch $\mathrm{M}$. The role of polymorphisms in ADAM33, a disintegrin and metalloprotease 33 , in childhood asthma and lung function in two German populations. Resp Res 2006;7:91.

60. Bridges LC, Sheppard D, Bowditch RD. ADAM disintegrin-like domain recognition by the lymphocyte integrins alpha4beta1 and alpha4beta7. Biochem J 2005;387:101-8.

61. Wiester LM, Giachelli CM. Expression and function of the integrin alpha9beta1 in bovine aortic valve interstitial cells. J Heart Valve Dis 2003;12:605-16.

62. Undarmaa S, Mashimo Y, Hattori S, Shimojo N, Fujita K, Miyatake A, Doi S, Kohno Y, Okamoto Y, Hirota T, Tamari M, Hata A, Suzuki Y. Replication of genetic association studies in asthma and related phenotypes. J Hum Genet 2010;55(6):342-9. Epub 2010 Apr 16.

63. Wu X, Li Y, Chen Q, Chen F, Cai P, Wang L, Hu L. Association and gene-gene interactions of eight common single-nucleotide polymorphisms with pediatric asthma in middle china. J Asthma. 2010;47(3):238-44. 